\section{A $(\mathbb{C}$ liniral enture}

\author{
ON \\ G E N C' V A L G U M . \\ Delivered at the Post-Graduate College and Polyclinic. \\ By CHARLES A. MORTON, F.R.C.S., \\ Professor of Surgery in University College, Bristol ; Surgeon to the \\ Bristol General Hospital and the Hospital for \\ Children and Women.
}

The Nature of the Bony Deformity which causes Genu VALGUM.

Gentlemen,-In $1897,{ }^{1}$ in the early days of skiagraphy, I had a skiagraph taken of a case of genu valgum in a child, and this showed, as clearly as skiagraphs of only partly-ossitied epiphyses can show, that elongation of the internal condyle of the femur and obliquity of the knee-joint, usually described as occurring in this condition, did not exist, but that the deformity was due to curvature of the tibia and fibula. ${ }^{2}$ This was entirely at variance with the pathology of the deformity given in all the textbooks of surgery; but after the publication of my communication, Mr. Noble Smith and Mr. Muirhead Little wrote to the BrITISH MEdical Journal and stated $^{3}$ that they had described such curvatures of the leg bones as I referred to as not uncommon in genu valgum. Mr. Noble Smith pointed out that in 1882 , in his book on the surgery of deformities, he had stated that he considered such curvatures, and not elongation of the internal condyle, to be the usual cause of genu valgum ; and Mr. Little said ${ }^{4}$ that in a monograph on the subject, also published in 1882 , he described these curvatures of the leg bones in genu valgum, and that in examining museum specimens of this deformity he had found the elongation of the internal condyle and the curve of the femur described by Macewen were seldom obvious, but that the deformity depended on an inward convexity of the upper end of the tibia and fibula.

I have referred to these books, and also to Macewen's work on genu valgum and other rickety deformities. ${ }^{5} \mathrm{Mr}$. Noble Smith seems to have been the first surgeon to publish a correct opinion as to the importance of the curvature of the leg bones in genu valgum, and this opinion was formed from a clinical examination of cases only. Dr. Little and Mr. Muirhead Little state in their joint work on genu valgum "that curvature of the tibia is sometimes a more prominent fact in rickety genu valgum than femoral curvature or inward inclination of the knee-joint." They, however, "refer knock-knee in all its forms primarily to relative or absolute weakness and relaxation of the structures composing and surrounding the knee-joint."

Macewen found defermity in the tibia in ro per cent. of his cases, but he regarded it as unimportant in the production of genu valgum in the vast majority of cases, and as only requiring osteotomy of the tibia in "very aggravated" ones. He thus describes the tibial deformity: "The tibial shaft is placed at an angle to the head of the bone, the lower part of the limb running outwards." In two instances, he says, he observed a somewhat similar deformity, but it commenced towards the lower portion of the upper third of the tibia, and he remarks that, as the femur was unaffected, they were really not cases of knock-knee at all. Such tibial curves he therefore regarded as having very little, if anything, to do with the production of ordinary genu valgum; and yet it is obvious that, If such curves are at all marked, unless they are compensated for by other pathological changes, they must be a most potent factor in the production of genu valgum.

Macewen's view that genu valgum is due to deformity in the lower end of the femur-chiefly to a curve with the convexity inwards but partly to an elongation of the internal condylehas been generally accepted. But all Macewen's observations seem to have been made from the clinical examination of cases. Before skiagraphs showed the shape of the bones in genu valgum, it was very difficult to get reliable information as to their exact shape. It is very rarely indeed that the opportunity occurs to make a thorough necropsy of the limb in this deformity. Mikulicz, however, many years ago pub. lished an account of the changes in the bones found post mortem. Before the days of antiseptic surgery I fear some osteotomies for genu valgum furnished some of these cases, but they were not Mikulicz's own cases I believe. He found an obliquity of the knee-joint from abnormal descent of the internal condyle, due to an increased growth at the lower end of the diaphysis, but he also found deformity of the tibia. The only recent description of the pathology of genu valgum based on necropsies that I can find is one by Professor Symington ${ }^{6}$ from the examination of a body in which very marked genu valgum was present, found in the dissecting room. He says the deformity in the tibia contributed more to the production of genu valgum than the deformity in the femur. He described the deformity of the tibia as an excessive growth on the inner side of the upper part of the diaphysis; but from his drawing of the bones I should myself describe it as a curve of the diaphysis outwards, immediately below the head, combined with a general curve of the fibula. He says there was no curve in the femur, and no elongation of the internal condyle, but that here also there was an excessive growth of the lower and inner end of the diaphysis; but he does not figure the whole femur, and he has drawn the lower end at an impossible angle. When the drawing is tilted so that the line of the femur approaches to the normal direction, there certainly then appears to be an obliquity of the lower end of the bone which would partly cause the genu valgum. This incorrect representation of the position of the femur is no doubt mace to get the picture on the same plate with another, but, unfortunately, it has been reproduced in this position in a recent book on orthopaedic surgery.

I have already referred to $\mathbf{M r}$. Muirhead Little's statement that he has examined some museum specimens of genu valgum, and found the leg bones commonly curved but the elongation of the internal condyle not obviocis. ${ }^{7}$ The pathological examination of cases of genu valgum then, though very rarely made, seems to have invariably shown a deformity of the tibia, but in some cases also in the lower end of the femur.

I soon found that my first result of skiagraphic investigation into the nature of genu valgum was not an exception. Case after case revealed the same condition, and in 1898 I wrote a paper ${ }^{8}$ describing this condition more fully, and advocating osteotomy of the tibia rather than of the femur. This operation had, of course, occasionally been done before; but my object in writing this paper was to call attention to the fact that, in children at any rate, curvature of the leg bones was the rule and not the exception, and to advocate osteotomy of the tibia rather than the femur in all these cases. I have now 25 skiagraphs of cases of genu valgum, showing the shape of the bones in more than 40 limbs, and from an examination of these $I$ am able to say that this curve in the tibia and fibula is the essential condition in the production of genu valgum in nearly all cases, that an abnormal descent of the internal condyle is the exception, and that in none of my cases is it present without a deformity of one or both leg bones, and that when present-with the exception of one case-it is clearly a subsidiary cause of the deformity, the latter depending almost entirely on the curvature of the leg bones.

When I published my last paper on the subject I was only able to write about the pathology of genu valgum in children. Since then I have had 4 cases in young people in whom the lower epiphysis of the femur and the upper epiphysis of the tibia were well ossified, and hence the shape of the bones forming the knee-joint could be ascertained more accurately than in children with imperfect ossification of the epiphyses, though these children show the curves of the tibia and fibula perfectly. I have also in my possession a skiagraph of a child old enough to show the outline of the epiphysis quite clearly. Out of these 5 cases, in 3 the knee-joint is perfectly transverse, and the deformity depends entirely on the curvature of the leg bones (Figs. 2 and 6, p. 1530). In one of the others the knee-joint is slightly oblique in one limb from a tilting down of the epiphysis on the inner side by excessive growth of the unossified tissue at the epiphyseal line on the inner side. The epiphyseal portions of both internal condyles are slightly elongated. This is not, however, a cause of the genu valgum, as the elongated condyle is received in a depression on the inner aspect of the 
head of the tibia, and, although the elongation of the epiphyseal portion of the condyle is the same on the two sides, on the side on which the tilting of the whole epiphysis is not present the joint is perfectly transverse. The chief deformity in this case lies in the shaft of the tibia (Figs. 9 and 10, p. 1531). In the only other case in which a change in the femur in any way causes the deformity the epiphyseal portions of the condyles are slightly, elongated and the tibia pushed out, but the curve in the tibia is as important an element in the case.

In one of the cases in which the knee-joints are transverse, and therefore the deformity cannot be caused by a change in the femur, the epiphyseal portions of the internal condyles are slightly elongated, but as in the case just referred to they are received in depressions in the head of the tibia, and do not tilt this bone outwards. The deformity depends entirely on the curved condition of the leg bones (Diagram I, A).
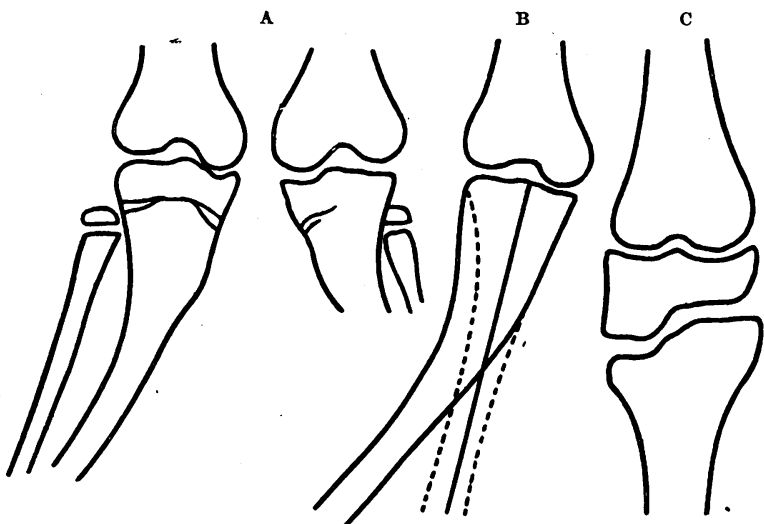

Diagram No. I.-A, diagram made from two skiagraphs, one of both knee-joints and the other of one leg. $B$, the dotted jine shows the small amount of genu valgum a slight elongation of the condyle will produce, if it tilts the tibia outwards. The tibia of shape $A$. without.a depression in inner side of head, is also applied to such

In these three cases in which the skiagraphs indicate some elongation of the internal condyle, it is clearly the epiphyseal portion of the condyle which is overgrown, and not the lower end of the diaphysis as Mikulicz described. I am inclined to think that it may be really secondary to the tibial curve for as the result of this curve the weight of the body is taken off the internal condyle and transmitted mainly through the external condyle, and if pressure is removed excessive growth may result. I have here a print of a skiagraph which shows in a most remarkable way the effect of removal of pressure from one condyle as a cause of increased growth. The head of the tibia on one side has become considerably depressed from old necrosis of the bone, and into the hollow thus formed the overgrown condyle of the femur descends (Diagram I, c.

In the cases in which the children were young, and the epiphyses were imperfectly ossified, it is not possible to be absolutely sure of the exact outline of the articular ends; but if we take them as a whole-the lower line of diaphyses and the portion of ossified bone in the epiphysis together-we can, I think, form a fairly correct idea of their shape. They do not, I believe, show abnormal descent of the inner condyle or an oblique knee-joint. In three of the skiagraphs taken at this early age the line of the lower end of the diaphysis seems to slope a little obliquely downwards on the inner side ${ }^{9}$ but if the joint were really oblique, then the upper line of the diaphysis of the tibia should slope in the same direction, whereas it does so in only one of these cases. Therefore there is only one such skiagraph which can suggest that any obliquity of the knee-joint is present. But in no fewer than three cases the line of the lower end of the diaphysis of the femur is oblique in the opposite direction, and in one of these the obliquity is present in the same direction in the upper line of the diaphysis of the tibia, and might, therefore, suggest that the knee-joint was oblique in a direction which would tend to correct the genu valgum. But I feel sure we cannot regard the direction of the lower end of the diaphysis alone as an indication of the line of the joint surface; for in several skiagraphs the upper end of the diaphysis of the tibia appears oblique, and in nearly every case in which that obliquity is present the inner end appears higher than the outer, but this cannot indicate that there is an elongation of the inner tuberosity of the tibia as has been suggested. ${ }^{10}$ In Diagram 2, Fig. I, I have drawn a tibia with an elongated inner tuberosity, and in Fig. 2 the tibia of this shape is ap-
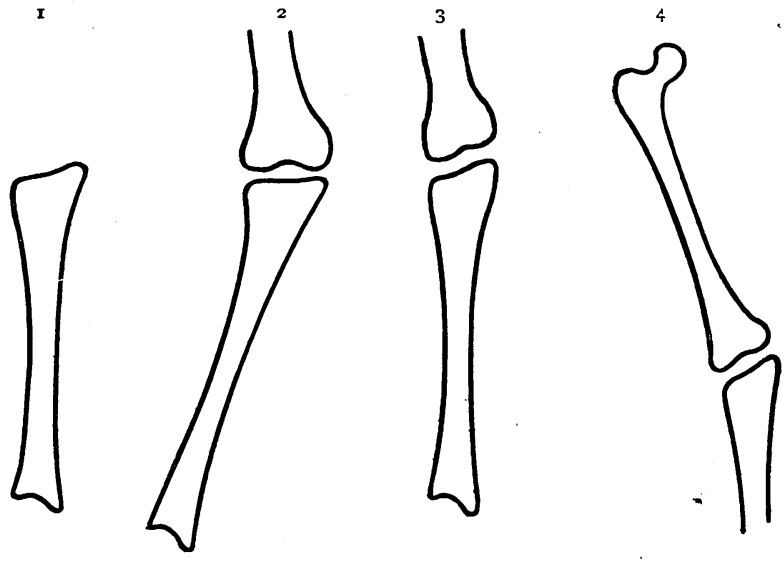

Diagram 2.

plied to the lower end of the femur. Now if a skiagraph were taken of this it would show not an oblique but a transverse upper surface of the tibia. An elongated inner tuberosity of the tibia could only appear as an oblique upper line to the tibia if the lower end of the femur were oblique, as in Fig. 3 , or if the femoral head could be thrown outwards, as in Fig. 4, or a wedge-shaped space could exist in the joint, which would be impossible.

I think we must disregard these oblique lines at the lower end of the diaphysis of both the femur and tibia in skiagraphs of imperfectly ossified bones or we may be led into very erroneous conclusions as to the shape of the bones at the knee-joint.
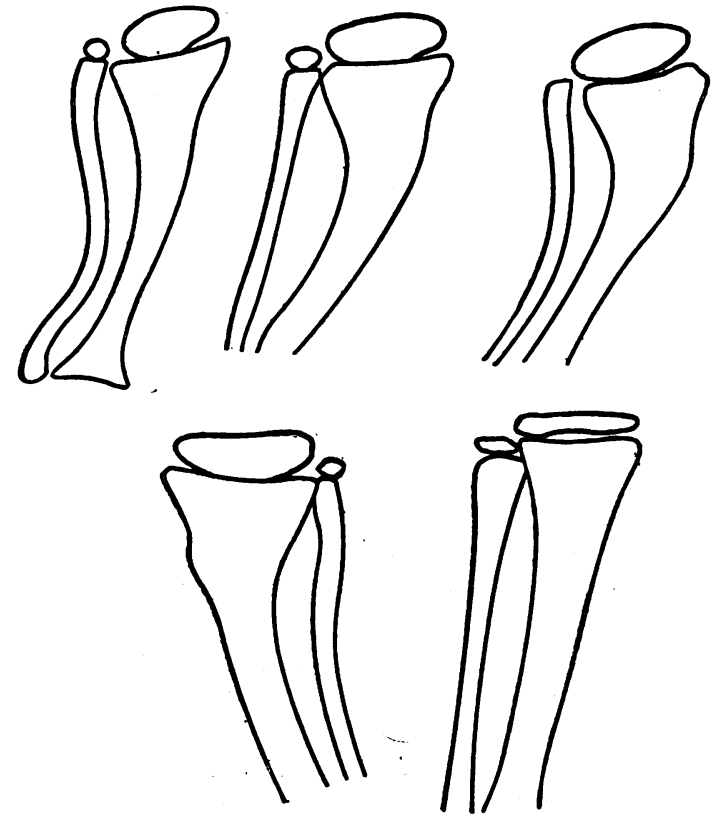

Diagram 3.

The form of curvature in the leg bones varies greatly. I have drawn in Diagram 3 some of the different types of deformity. In some cases the fibula is as much curved, or has 
even a sharper curve, than the tibia. In others with marked obliquity of the tibia the fibula is quite straight. There may be very marked, almost angular, curving out of the tibia just below the head, or a gradual curve outwards along the whole bone.

The Operative Treatnent of the Deformity.

In connexion with what I have said about the deformity of the bones in genu valgum, I will at once proceed to discuss the operative measures which may be undertaken for its correcticn, and later on speak of spontaneous rectification of the deformity. the use of splints and irons, and discuss the question of operation.

I do not propose to say anything in this lecture about osteoclasia. I have had no experience of it in the treatment of genu valgum. I will speak only of osteotomy, and this I think should be done on the bones which are deformed and not on the normal, or almost normal, femur. There is no doubt we can get perfectly straight limbs by Macewen's operation on the femur, even though the deformity is wholly in the leg bones. I have done so myself-but we produce an oblique knee-joint (Diagrams $4, \mathrm{c}$ and $\mathrm{D}$ ), and an oblique knee-joint cannot be a satisfactory position of the joint when the patient is walking about. And not only is the knee-joint made oblique by Macewen's operation, but it is deflected out of the normal line (Diagram $4, D$ ). The weight of the body is usually transmitted in a line passing from the head of the femur through the centre of the knee and ankle-joints.

After Macewen's operation the leg is deflected inwards from this line, unless in putting up the limb after the osteotomy the lower fragment of the femur is displaced outwards. The obliquity of the knee-joint, and the inward deflection of the leg from the normal line of weight transmission I have represented in Diagrams $\mathrm{C}$ and $\mathrm{B}$.
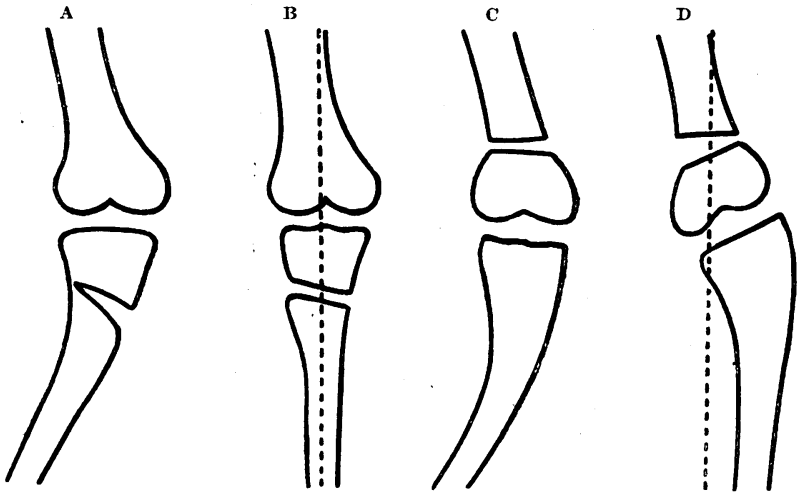

Diagram 4.-A, wedge removed from tibia. B, correction of deformity by bringing sides of wedge space together. c, section of femur in Macewen's operation. D, correction of genu valgum but production of oblique knee-joint. Space left in femur fills up by new bone. Dotted line represents line of normal transmission of weight.

I think, therefore, the best plan is to remove a wedge from the tibia. In some cases I have had also to divide the fibula, but often not, even in cases in which it was much curved. I know that osteotomy of the leg bones has been occasionally performed by surgeons; indeed the earliest operation for genu valgum by Mayer of Würzburg in I85I, was an operation of the same kind as I now practise. But I maintain that it should be the routine operation for these cases, and that a division of the femur should only be practised when a skiagraph shows that a deformity there with marked obliquity of the knee-joint is an essential element in the causation of the genu valgum, and that the tibial deformity is subordinate to this. Such a case I have not myself met with.

I have done osteotomy of the leg bones for genu valgum in 17 limbs in II patients. I now propose to give you the result of my experience of this operation. It has been stated that this form of osteotomy is more dangerous than Macewen's, because the vessels in the leg are more likely to be injured than the popliteal vessels, and Mayer did wound the posterior tibial vessels and nerve in one of his cases. Very great care not to injure these vessels and also the ante- rior tibial artery and nerve should, of course, be exercised in the removal of the wedge. I have not myself wounded any important vessel or nerve, but I admit that the upper third of the tibia is not an easy position to remove bone from, and that undoubtedly Macewen's operation is much easier. The wedge should be removed as high up in the tibia as possible, just below the tubercle, and the breadth of the base of the wedge must depend on the degree of curvature. We should not aim at the removal of a transverse wedge, but of one with the apex directed obliquely upwards, as shown in Diagram 4, A. This allows of a better correction of the deformity. I say "aim at the removal of a wedge directly upwards," because when we get through the compact bones into the soft cancellous structure it is not easy to maintain an exact wedge form if we remove the bones in fragments; and I have never ventured in this position-so near the tibial vessels-to cut right through the bone towards the calf or anterior interosseous space. After sawing a wedge in the direction described, out of the compact bone on the inner aspect of the tibia, I have always very cautiously removed the underlying bone in pieces, partly by Adams's saw, and partly by chisel and mallet. In most cases I do not even divide the periosteum on the posterior and external aspect of the bone. A gap more or less wedge-shaped is formed, and, if enough bone has been removed, when the wedge space is closed up by bringing the lower part of the leg downwards, the genu valgum will be corrected (Fig. B). If enough bone has not been removed, another slice can be taken off quite easily, without fear of injury to the underlying structures, for the exact depth of the bone will now be apparent. If rectification of the deformity cannot be obtained because of the curvature of the fibula, that bone must also be divided. In my first operation I did this at the seat of greatest curvature at the middle of the bone, but I found it here so abnormally close to the tibia, and the interosseous space so narrow, I thought the risk of injury to the anterior tibial artery and nerve a serious one, and I have ever since, when it has been necessary to divide the bone, done so where it is more superficial in the lower third; with the exception of an extreme case of genu valgum in which I had considerable difficulty in correcting the deformity, and removed a quarter of an inch from the upper end. In some of my earlier cases I found a tendency for the tibia to bow backwards at the seat of osteotomy. This defoimity disappeared very quickly, but it can be entirely prevented by placing a pad under the bones here during the healing of the wound. I have had a special splint made for the operation. It is a combination of a long Liston with a back splint to support the divided leg bones, and one of its great advantages is that it has a travelling footpiece, which allows the foot and leg bones below the seat of osteotomy to be brought well to the normal line of the limb. The footpiece travels across the breadth of the lower end of the back splint, and can be fixed by a screw beneath in any position.

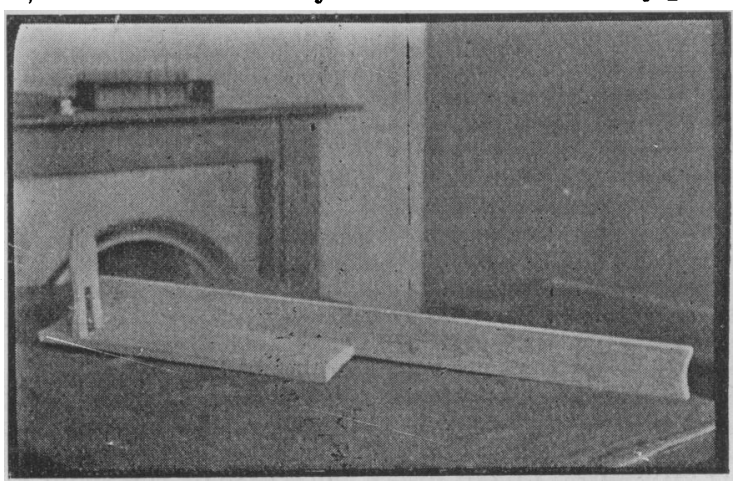

Splint used after operation.

I have been very well satisfied with the results of these operations on the leg bones, and from the lantern slides (Photographs I to iI) you can judge for yourselves as to whether the limb can be thus straightened.

I need hardly say that I have had no mortality from the operation, and the wound suppurated in one limb only. I have been able to examine the worst case of genu valgum I 
have operated on three years after the operation, and there has been no relapse. One other case I have been able to examine a year after the operation, and two, two years after the operation, and found no relapse. Three cases are quite recent ones. I have found two relapsed cases in young children; the rest I cannot examine.

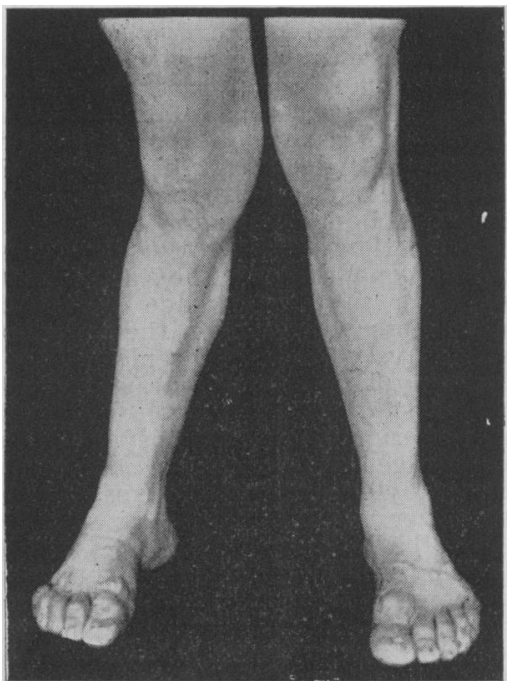

Fig. x.-Before operation.
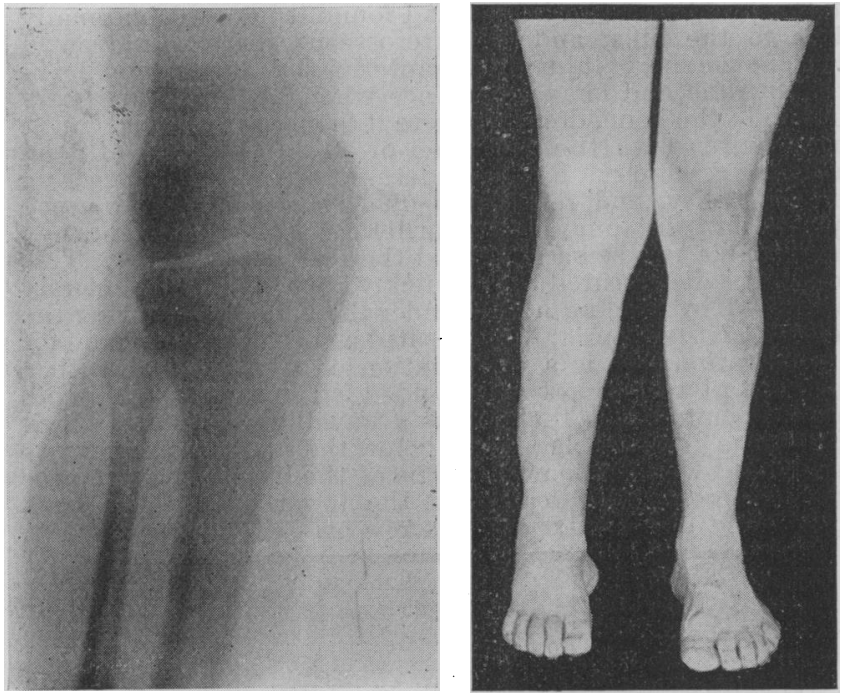

Fig. 2.-Skiagraph showing condition of bones at knee-joint from case shown in Fig. $x$.

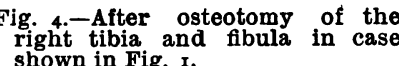
shown in Fig.

Spontaneous Rectification of Deformity.

We must recognize the fact that this rickety deformity tends in many instances to become spontaneously corrected during the growth of the hone. I may remind you of an instance of this given by Mr. Edmund Owen in his book on Surgical Diseases of Children. He forcibly straightened the bent tibia in one leg and kept the child off her feet for a year. By the end of that time the other leg had grown equally straight. I have lately had a case of the same kind myself. I straightened the limb most deformed by genu valgum, and after three months' rest the other, which was certainly much less deformed than the one on which osteotomy was done, grew quite straight. The patient was 16 years of age. I must say a splint was applied to the limb which grew straight for some weeks while the patient was in bed after the osteotomy, but the limb was constantly rotating in it, and no pressure was maintained and its use

was abandoned. The spontaneous straightening of the leg (left) is shown in the two photographs taken before and three months after osteotomy (Figs. 5 and 7 ).*

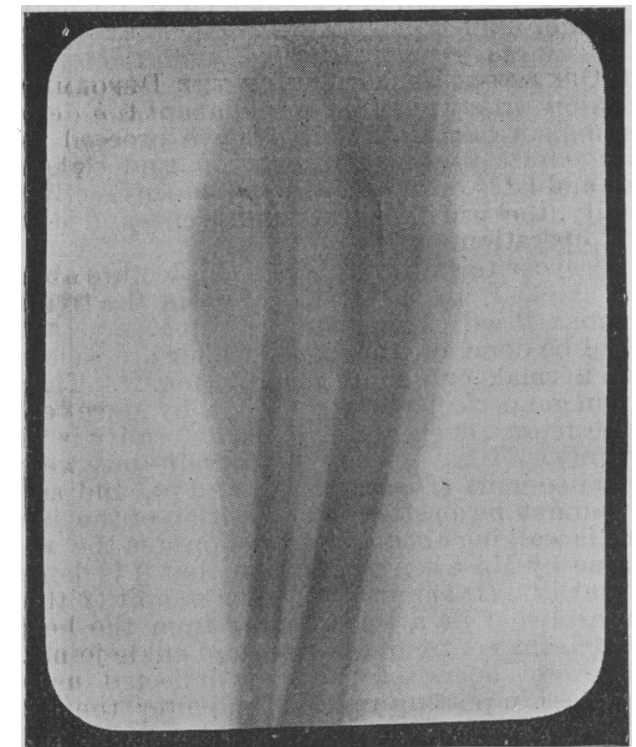

Fig. 3.-: kiagraph of leg bones of case shown in Fig. I.

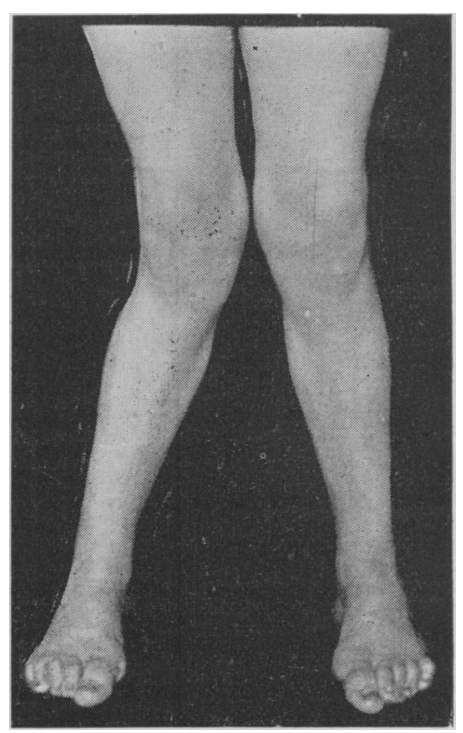

Fig. 5.-Before operation.

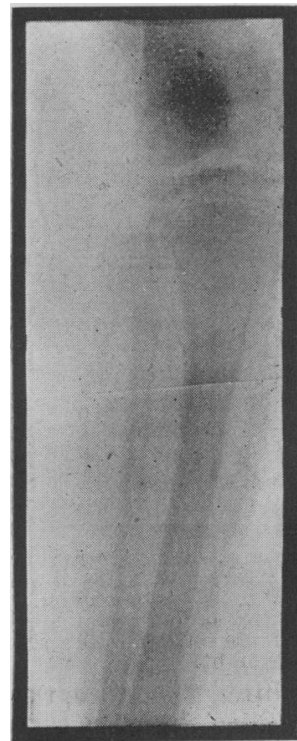

Fig. 6.-Skiagraph of case shown in Fig. 5 ; two \&kiagraphs were taken one of his knee and another of leg bones; the prints from these were oined and photographed, and was made.

Professor Ogston ${ }^{11}$ says that in a child 3 years of age with genu valgum, in whom the leg deviated to an angle of 10 degrees from the normal direction, the deformity completely disappeared in eighteen months with no other treatment than the administration of cod-liver oil. Kampe ${ }^{12}$ has shown how frequently rickety deformity in the legs undergoes spontaneous cure in children under 6 years of age. I certainly think that the prevention of pressure on the bones by keeping children off their feet must assist the tendency to

* Indeed the same thing is apparent in Fig. 4. In Fig. $x$ it appeared so because the girl is evidently leaning over to that side to take the weight off the osteotomized leg. Really the genu valgum in the left leg was increasing. 


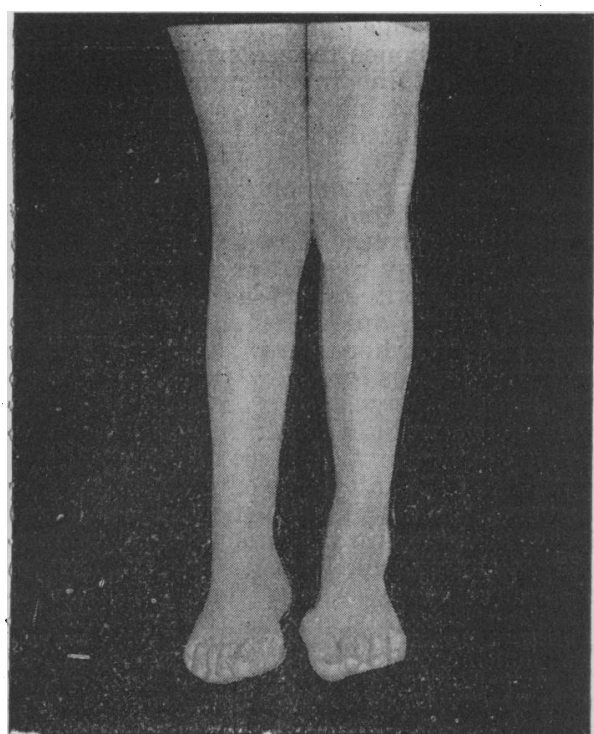

Eig. :--Aiter osteotomy of right tibia in case shown in Fig 5 .

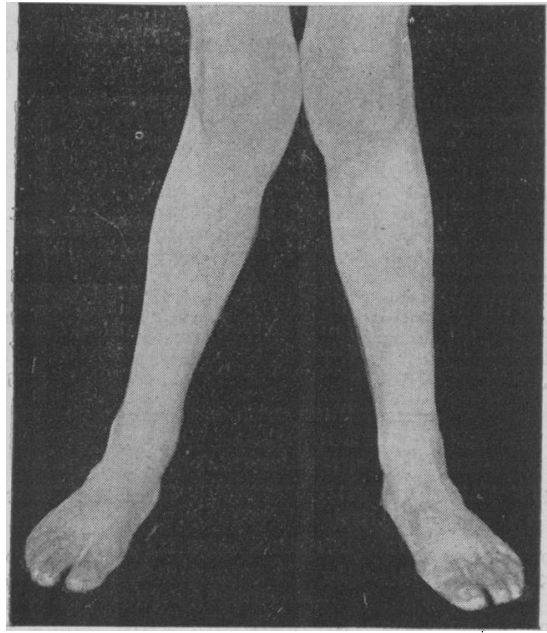

Fig. 8.-Before operation.

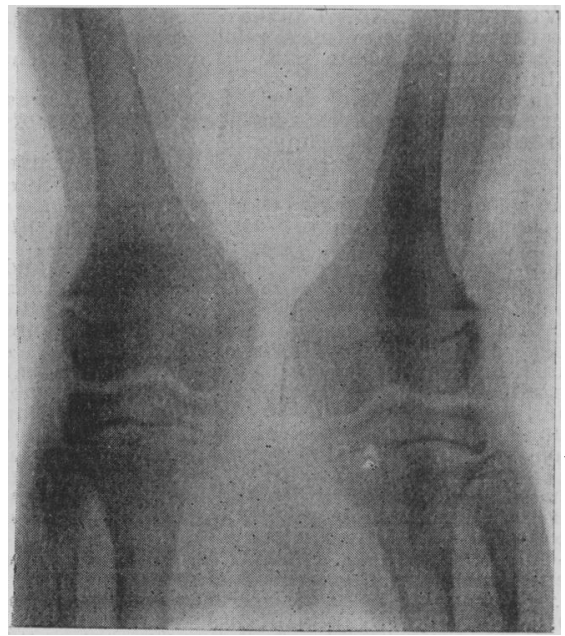

Fig. 9.-Skiagraph of case shown in Fig. 8. spontaneous cure; but there is no doubt that; in spite of continued walking, it sometimes takes place, and any splints or leg irons in use in such cases get more credit than they deserve. We are told by some surgeons of an enormous proportion of cases of genu valgum which they are able to cure by splints or irons whilst the children are running about as usual. I feel sure that in these cases-perhaps not quite as numerous as we are given to suppose-the tendency to spontaneous cure is the important factor, though no doubt the splints and irons support the weak bone and prevent further bending.

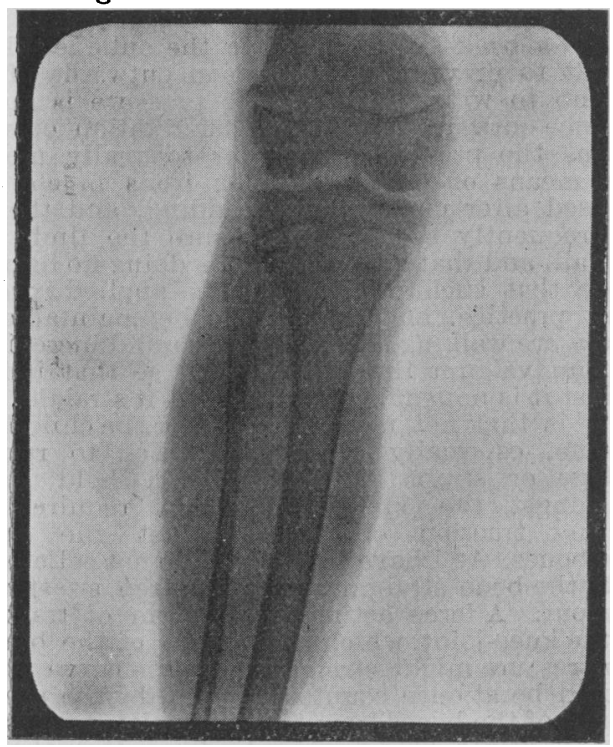

Fig. 10.-Skic graph of leg bones of Case 8.

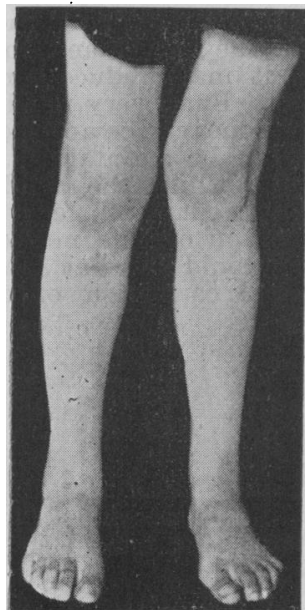

Fig. Ir.-After osteotomy of tibia and fibula in right leg in case shown in Fig. 8.

The Action of Splints.

I believe that light splints may be used with advantage in order to keep children off their feet and to support the soft and yielding bones, but I have very little faith in splints, as usually applied, to mould the bones into better position. I admit that bones may be thus moulded, for if the bones yield to the pressure brought to bear on them in walking, in the production of genu valgum, certainly they may be moulded straight again by pressure or traction in an opposite direction. As other examples of the way in which solt rickety bones yield to pressure, I may remind you of the deformity of the chest due to respiratory movement, and the distortion of the pelvis from the pressure of the weight of the body transmitted through the pelvis to the femoral heads. But in the great 
majority of cases of genu valgum treated by splints in our hospital out-patient rooms, sufficient pressure to mould the bones is not applied; and even in those cases in which it is applied, the bandage and strapping very soon loosen, or the limb rotates just a little, and it is no longer exercised. Even with outside irons and leather bands I doubt very much if sufficient pressure is kept up to mould the bones. Only with the most careful padding with wool or some soft material over the inner aspect of the bone where traction outwards is applied, and over the outer malleolus where the splint will press, would the delicate skin of children stand pressure sufficient for this purpose.

Even with a back splint joined to the outside splint, it is very difficult to prevent some rotation outwards of a genu valgum limb to which considerable pressure is applied to draw the knee outwards, and the least rotation outwards at once lessens the pressure. In order to really mould the bones by means of splints and leg irons much pressure must be used after most careful padding, and the patient must be frequently seen to make sure the limb has not twisted at all, and that the pressure is doing no harm. I do not believe that such pressure can be applied in ordinary out-patient practice, and that it can be maintained while the children are walking about is to my mind incredible. To attach a genu valgum limb to a splint so that it is firmly fixed against it is not sufficient to mould it straight, and the probability is that not many hours after the child has been taken home, especially if it is allowed to run about, the bandage or straps no longer even hold the limb firmly againgst the splint. It must require continuously acting traction outwards against the splint to mould the bones. As I have just said, I do not believe a splint can mould the bone straight whilst children are standing or walking about. A force acting in the form of traction outwards at the knee-joint, which if the ends of the bones were free from pressure might straighten out the curve of the leg bones, would be at once counterbalanced by the pressure on the two ends of the bones from the transmitted weight of the body, for this would be a far greater force than the traction outwards against the splint. Indeed, it seems possible that when the patient is walking about, and the traction outwards cannot straighten out the curve, and this traction is only applied at the knee, it may produce a new curve as represented in Diagram 5, B. But I very much doubt if traction sufficient to mould the bones can be applied whilst the child is walking about. If it can be maintained under such conditions it can certainly act whilst the child is at rest, and so the gradual straightening out of the curve causing the genu valgum and the formation of this new curve would go on alternately, the result would be what I have represented in Diagram 5, c-a partial correction of one curve and the

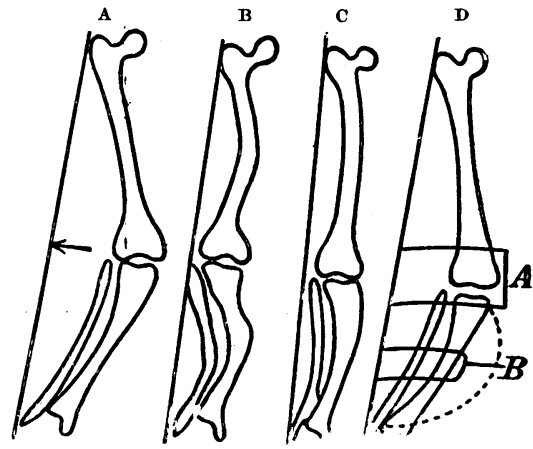

Diagram 5.-A, arrow shows direction of traction outwards towards splint; $\mathbf{B}$, effect if child constantly walking or standing; $\mathbf{C}$, effect splint; $B$, effect if child constantly walking or standing; C, effect of the limbs by.splint ; A, support at knee; B, support for leg.

formation of another. The obliquity outwards of the anklejoint would not be wholly corrected.

I think that the application of an outside splint of iron may. prevent the increase of genu valgum, even if the child runs about, and that the deformity may undergo spontaneous rectification whilst such apparatus are in use just as it may if no splints are employed. But if such support is given only to the knee, by a bandage or strap passing round the splint and the joint, the leg bones may continue to bend below as shown by the dotted line in Diagram 5, D, and therefore I think the shaft of the tibia, and even the lower end of the femur, should be supported also.

This has been much debated, and there is a great difference of opinion with regard to the time when this should be done, and as to what cases require it. Some surgeons never operate below a certain age; but do not agree as to what that age should be. Others only operate when a certain degree of genv valgum is present; but here, again, there is no agreement; and one surgeon operates for a few inches less than another. Again, some surgeons have such a strong faith in the value of splint treatment, you would think from what they say there are no cases splints cannot cure, and that all their patients, even with marked deformity, are content to go on year after year, with very gradual improvement. Mg own feeling $\mathrm{g}$ that in severe cases of genu valgum, even in young childre $n$, if there is reason to think that the stage of softening and yielding of the bones is over, osteotomy may be done, but no doubt the older the child the less the tendency to relapse. Often the parents of children with marked genu valgum are not content to employ splints month after month with a very slow improvement, or perhaps none at all, nor are they willing to keep their children off their feet for months; or, indeed, amongst the poor people, able to do so. They will have their children's legs straightened, even though we point out to them the risk of relapse without the greatest care for years after the operation. In older children, and in young adults in whom the deformity has quite, ceased to increase for some time, and in whom the deformity is marked, I should not hesitate to do osteotomy.

\section{NOTES AND REFERENCES.}

1 BRITISH MEdical JoURNAL, 1897, vol. $i$, p. 1347, 2 This skiagraph is reproduced in my paper in the BRITISH MEDICAL JouRNAL, r898, vol. $i$, p. roo4, Skiagraph No. I. 3 BRITISH MEDICAL JoURNAL, 1897, vol. i, p. 15x4, and vol. ii, p. 53. 4 Loc. cit. 5 Osteotomy, Macewen, 1880. 6 Trans. Royai Academy of Medicine in Ireland, vol. xiv, 1896. p. 409. T BRITISH MEDICAL JoURNAL, 1897, vol.i, p. 1514. 8 Ibid., 1898, vol. i, p. roo3. 9 An illustration of this is given in skiagraph No. $I$ in my paper in the BRITISH MEDICAL JOURNAL, r898, vol. i, p. IOO3. 10 BRITISH MEDICAL JOURNAL, 1897, vol. ii, p. 1638. 11 Ibid., r888, vol. ii, p. 1148.12 Bruns, Beitr. klin. Ch.

\section{SPINA BIFIDA :}

ITS OPERATIVE TREATMENT AMONGST OUT-PATIENTS. BY JAMES H. NICOLL, M.B.,

Extra Surgeon Children's Hospital : Assistant-Surgeon, Western Infirm ary; Consulting Surgeon, Ear Hospital; etc., Glasgow.

ON January inth, 1902, the two following cases were shown at a meeting of the Glaggow Medico-Chirurgical Society.

CASE 1.- G.M., a patient of Dr. Fotheringham, of Motherwell, was brought to the Glasgow Children's Hospital, at the age of 2 months, on August 2nd, 19or. (Fig. ris the reproduction of a photograph taken on that date.) otherwise healthy.

Operation - On August 6 th, four days later, the tumour was excised in operation.- On August The tumour proved to be a pure meningocele.

Progress. - Convalescence was uneventful. The child was nursed throughout by its mother, aided by an aunt, and instructed by the Surgical Sister, who visited the patient daily, dressed the wound on the one occasion on which it was thought advisable, and removed the skin sutures on the eighth day.

now nearly 8 months old. is in perfect health, and was shown to the Society. (Fig 2 is a reproduction of a photograph taken a month previously, that is, some four and a-half months after operation.

CASE II.-B. B., a patient of Dr. Wm. Ross, Glasgow, was brought to the Children's Hospital, at the age of 3 weeks, on November 17 th, 1901. (Fig. 3 is the reproduction of a photograph taken on that date.) The case differed in certain features from the foregoing, and, in demonstrating it to the students, attention was drawn to two points-(a) dimpling of the with and by palpation, and by transmitted light) (b) a considerable degree of paraplegia (evidenced by blueness of feet and legs, absence of voluntary movements of lower limbs, and the repeated development of spasticity on the attempt to excite reflex movement)

Operation.-On November $23 \mathrm{rd}$, a week later, the tumour was excised in the out-patient clinic, and the child thereafter nome in the care of its mother. On opening the sac during the operation there were found four nerve cords coursing over its wall, three on one side and one on the other. Attached to these cords were a number of whitish tumours ranging in size from:that of a pinhead to that of a large pea. The nerve 